\title{
Impact of Redox Condition on Fractionation and Bioaccessibility of Arsenic in Arsenic-Contaminated Soils Remediated by Iron Amendments: A Long-Term Experiment
}

\author{
Quan Zhang, ${ }^{1,2}$ Lixin Pei, ${ }^{1}$ Chunyan Liu, ${ }^{1}$ Mei Han, ${ }^{1}$ and Wenzhong Wang ${ }^{1}{ }^{1}$ \\ ${ }^{1}$ Institute of Hydrogeology and Environmental Geology, Chinese Academy of Geological Sciences, Shijiazhuang, China \\ ${ }^{2}$ China University of Geosciences, Beijing, China
}

Correspondence should be addressed to Wenzhong Wang; wwenzhong2005@163.com

Received 25 October 2017; Accepted 8 January 2018; Published 11 March 2018

Academic Editor: Meijing Zhang

Copyright (C) 2018 Quan Zhang et al. This is an open access article distributed under the Creative Commons Attribution License, which permits unrestricted use, distribution, and reproduction in any medium, provided the original work is properly cited.

\begin{abstract}
Iron-bearing amendments, such as iron grit, are proved to be effective amendments for the remediation of arsenic- (As-) contaminated soils. In present study, the effect of redox condition on As fractions in As-contaminated soils remediated by iron grit was investigated, and the bioaccessibility of As in soils under anoxic condition was evaluated. Results showed that the labile fractions of As in soils decreased significantly after the addition of iron grit, while the unlabile fractions of As increased rapidly, and the bioaccessibility of As was negligible after $180 \mathrm{~d}$ incubation. More labile fractions of As in iron-amended soils were transformed into less mobilizable or unlabile fractions with the contact time. Correspondingly, the bioaccessibility of As in iron-amended soils under the aerobic condition was lower than that under the anoxic condition after $180 \mathrm{~d}$ incubation. The redistribution of loosely adsorbed fraction of As in soils occurred under the anoxic condition, which is likely ascribed to the reduction of As(V) to As(III) and the reductive dissolution of Fe-(hydr)oxides. The stabilization processes of As in iron-amended soils under the anoxic and aerobic conditions were characterized by two stages. The increase of crystallization of Fe oxides, decomposition of organic matter, molecular diffusion, and the occlusion within Fe-(hydr)oxides cocontrolled the transformation of As fractions and the stabilization process of As in iron-amended soils under different redox conditions. In terms of As bioaccessibility, the stabilization process of As in iron-amended soils was shortened under the aerobic condition in comparison with the anoxic condition.
\end{abstract}

\section{Introduction}

The widespread contamination of soils with arsenic (As), caused by human activities, is a high environmental and toxicological concern. Several technologies, such as in situ chemical stabilization, phytoremediation, and soil washing, can be used to decrease As pollution in soils $[1,2]$. Among them, the in situ chemical stabilization implies the application of stabilizing amendments, which by chemical means reduces As mobility and bioaccessibility [3] and refer to the portion of As that can reach into groundwater [4]. Nowadays, ironbearing amendments, such as iron oxides, iron salts, zerovalent irons, and iron-rich industrial byproducts, are proved to be effective in remediating As-contaminated soils $[2,5-7]$.
Among zero-valent irons, nanoscale zero-valent iron and iron grit are the two most prevalent soil remediation agents [4].

The remediation efficiency of iron amendments such as iron grit to As-contaminated soils is commonly dependent on the proportions of labile and unlabile As fractions accounting for the total As in soils. Thus, it is essential to understand the stabilization/aging processes of As related to the change of As fractions in soils. And the stabilization/aging processes of As in soils not only depended on the properties of amendments but also were affected by some environmental conditions, such as temperature and redox conditions $[5,8-$ 10]. For instance, the crystallization of Fe (hydr)oxides and the diffusion of As in micropores from the outer layers into the inner complex are accelerated after the temperature 
TABLE 1: Physicochemical properties of the experimental soil.

\begin{tabular}{lc}
\hline $\mathrm{pH}$ & 7.67 \\
Organic matter $(\mathrm{g} / \mathrm{kg})$ & 28.7 \\
Total Fe $(\mathrm{g} / \mathrm{kg})$ & 43.1 \\
Free iron oxides $(\mathrm{g} / \mathrm{kg})$ & 17.0 \\
Amorphous iron oxides $(\mathrm{g} / \mathrm{kg})$ & 6.7 \\
Total Al $(\mathrm{g} / \mathrm{kg})$ & 93.7 \\
Total Mn $(\mathrm{g} / \mathrm{kg})$ & 0.627 \\
CEC $(\mathrm{cmol} / \mathrm{kg})$ & 12.7 \\
Particle size $(\%)$ & \\
Sand $(>0.05 \mathrm{~mm})$ & 31.8 \\
Silt $(0.002-0.05 \mathrm{~mm})$ & 55.6 \\
Clay $(<0.002 \mathrm{~mm})$ & 12.6 \\
As fractions $(\mathrm{mg} / \mathrm{kg})$ & \\
F1 & 0.045 \\
F2 & 0.082 \\
F3 & 0.199 \\
F4 & 2.59 \\
F5 & 1.77 \\
F6 & 16.5 \\
\hline
\end{tabular}

elevated, resulting in the transformation of labile fractions of As into unlabile fractions $[5,9]$. The forms of As and Fe-hydroxides in soils are commonly affected by the redox conditions $[10,11]$. However, the effect of redox condition on the stabilization processes and bioaccessibility of As in soils amended by iron grit are little known.

The present study aims to (1) investigate the effect of redox condition on As fractions in As-contaminated soils remediated by iron grit in a long term and (2) evaluate the bioaccessibility of As in remediated (iron grit) soils and unremediated soils. Fractions of As in soils were extracted by the sequential extraction procedure (SEP). The results will be beneficial to understanding of the stabilization processes and remediation efficiency of As in soils amended by iron grit under different redox conditions.

\section{Materials and Methods}

2.1. Soil and Amendment Characteristics. The soils were collected from the upper $10 \mathrm{~cm}$ of an agricultural land irrigated by sewage in South China. Soil samples were air-dried, ground, and passed through a $0.9 \mathrm{~mm}$ sieve after discarding debris and finally homogenized in advance of analysis. The detailed physicochemical properties of the experiment soil are shown in Table 1, and the related analytical methods have been discussed in our previous publication [11]. The iron grit used for soil additive was purchased from Tianjin evergreen chemical reagent manufacturing Co., Ltd. (China).

2.2. Soil Preparation and Handling. Three samples were taken from the above composite soil with $300 \mathrm{~g}$ each. The first and the second ones were spiked by $\mathrm{Na}_{3} \mathrm{AsO}_{4}$ solution and made the concentrations of As in soils up to $100 \mathrm{mg} / \mathrm{kg}$ and then added with $6 \mathrm{~g}$ of iron grit $(2 \%, \mathrm{w} / \mathrm{w})$ and mixed immediately.
The first one was added with relatively small volume and high concentration of As solution to make the soil moisture equal to field capacity, which is labeled as $\mathrm{S}_{\mathrm{IA}}$. The second one was spiked with relatively big volume and low concentration of As solution to make the soil supersaturated, which is denoted as $S_{I N}$. The third one was treated with the same process of $S_{\text {IN }}$ but with no addition of iron grit and is denoted as $S_{N} \cdot S_{N}$ and $\mathrm{S}_{\mathrm{IN}}$ represent soils under the anoxic condition, and the latter one added iron grit. By contrast, $\mathrm{S}_{\mathrm{IA}}$ with the addition of iron grit represents soils under the aerobic condition. All samples were incubated in an artificial climate chamber with a temperature of $25^{\circ} \mathrm{C}$ and a humidity of $65 \%$. $\mathrm{S}_{\text {IA }}$ was opened and maintained at the soil moisture of field capacity, while $\mathrm{S}_{\mathrm{N}}$ and $\mathrm{S}_{\mathrm{IN}}$ were sealed and maintained a supersaturated condition. At different times $(0 \mathrm{~d}, 3 \mathrm{~d}, 10 \mathrm{~d}, 30 \mathrm{~d}, 60 \mathrm{~d}, 120 \mathrm{~d}$, and $180 \mathrm{~d}$ ) after incubation, soil samples were collected and freeze-dried for $24 \mathrm{~h}$ in a vacuum before the extraction of As fractions [12].

2.3. Sequential Extraction Procedure and Quality Control. The dried samples were ground and mixed after being collected, and $1.00 \mathrm{~g}$ of samples was weighted into acid-washed $50 \mathrm{ml}$ centrifuge tubes. All sample analyses were performed in duplicate. The fractionation of As in soils was determined by one modified Tessier's SPE [11]. Six fractions are denoted as $F 1, F 2, F 3, F 4, F 5$, and $F 6$ and are corresponding to water soluble fraction, exchangeable fraction, loosely adsorbed fraction, strongly adsorbed and organically bound fraction, $\mathrm{Fe}$ and $\mathrm{Mn} / \mathrm{Al}$ oxides bound fraction, and the residual fraction. The details are shown in our previous study [11]. In this study, all reagents were analytical grade or better. The concentrations of As in the extractions were determined using an atomic fluorescence spectrophotometer (AFS-610A model, Beijing, China). A standard reference soil GSS-16 (National Center for Standard Reference Material, Beijing, China) was used for quality control of the acid digestion. The recovery for As in the standard reference soil GSS-16 was $98.7 \%$. The errors for the sum of As measured in all six fractions to a single total As determination were within $\pm 18.5 \%$.

\section{Results and Discussion}

3.1. Influence of Iron Grit Amendment on As Fractions in Soils. As shown in Figure 1, there was significant difference for all As fractions between iron grit amended soils $\left(\mathrm{S}_{\mathrm{IN}}\right)$ and unamended soils $\left(S_{N}\right)$ at initial time $(0 \mathrm{~d})$. It is worth mentioning that the determination of As fractions at initial time was after $24 \mathrm{~h}$ freeze-drying in this study. The labile fractions such as $F 1, F 2$, and $F 3$ in $S_{\mathrm{N}}$ accounted for $32 \%$, $14 \%$, and $27 \%$ of the total As, respectively, and were far higher than that in $\mathrm{S}_{\mathrm{IN}}$. In contrast, the less mobilizable fractions such as F4 and F5 in $S_{\mathrm{N}}$ accounted for $11 \%$ and $4 \%$ of the total As, respectively, and were far lower than that in $S_{\text {IN }}$. This indicates that iron grit has a rapid effect on the decrease of labile fractions of As in soils and a large proportion of labile fractions of As in soils transformed rapidly into less mobilizable fractions after the addition of iron grit. This is likely to be ascribed to the rapidly increase of iron oxides in 


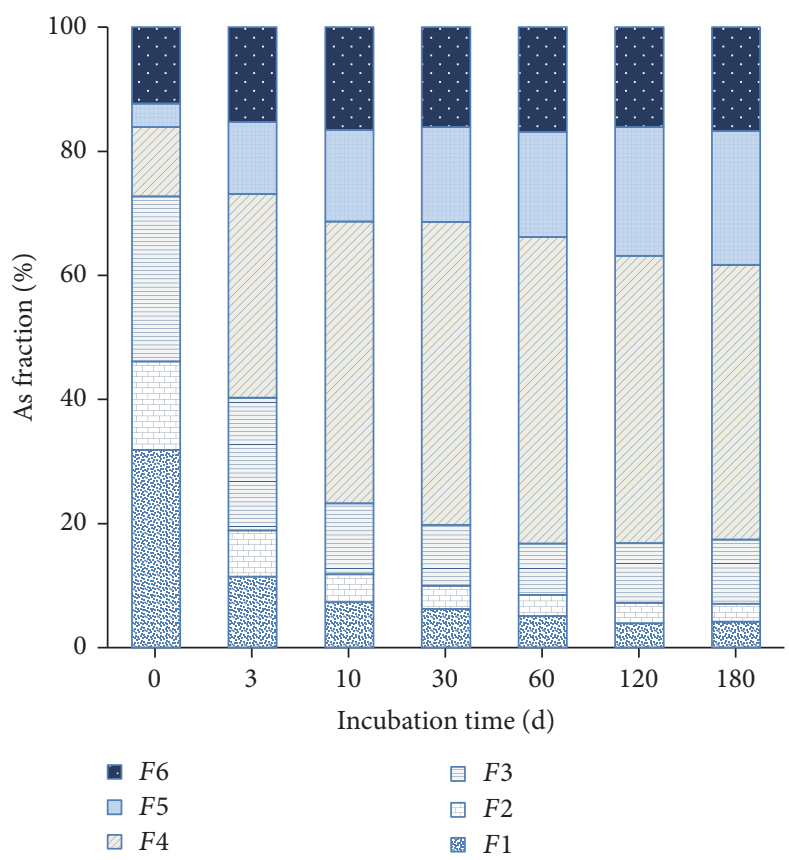

(a)

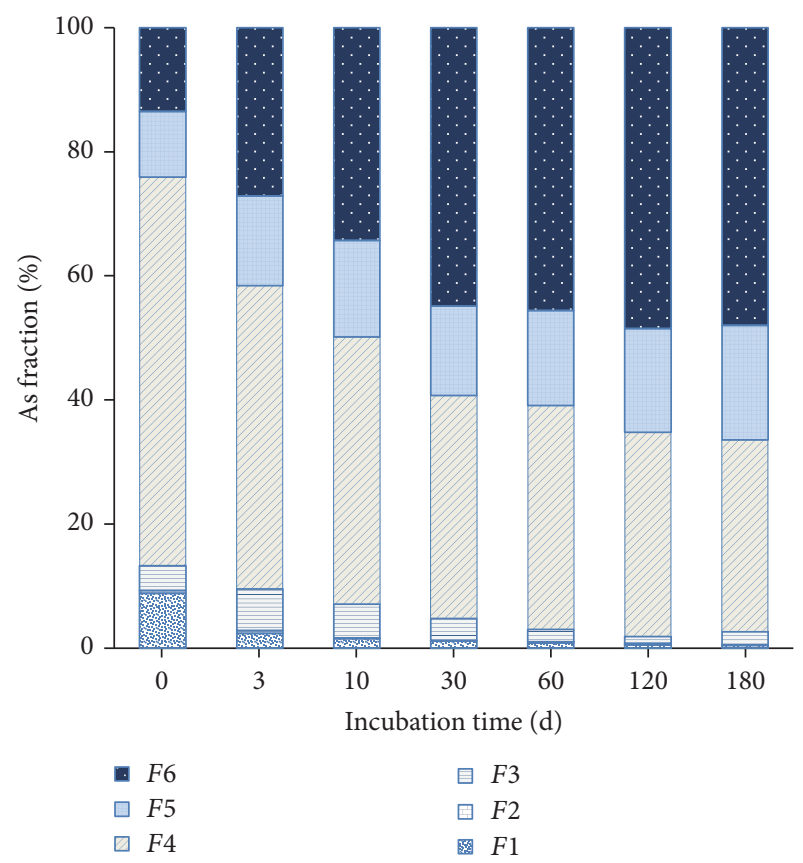

(b)

FIGURE 1: The fractions of As in iron grit amended and unamended soils at different time under the anoxic condition ((a) $\mathrm{S}_{\mathrm{N}}$, (b) $\mathrm{S}_{\text {IN }} ; F 1-$ water soluble fraction, F2-exchangeable fraction, F3-loosely adsorbed fraction, F4-strongly adsorbed and organically bound fraction, F5-Fe and $\mathrm{Mn} / \mathrm{Al}$ oxides bound fraction, and $\mathrm{F} 6$-residual fraction).

soils after the addition of iron grit, because iron oxides have strong adsorbed ability on water soluble As $[13,14]$. After the incubation, $F 1$ in both of $S_{N}$ and $S_{\text {IN }}$ decreased significantly within $120 \mathrm{~d}$ and were from $32 \%$ and $9 \%$ of the total As to $4 \%$ and less than $1 \%$, respectively. $F 2$ in $S_{\mathrm{N}}$ decreased from $14 \%$ to $3 \%$ and reached a steady state within $60 \mathrm{~d}$, while it in $\mathrm{S}_{\mathrm{IN}}$ was negligible during the whole incubation period. $F 3$ in $\mathrm{S}_{\mathrm{N}}$ decreased from $27 \%$ to about $10 \%$ and reached a steady state within $30 \mathrm{~d}$, while it was increased firstly from $4 \%$ to $7 \%$ within $3 \mathrm{~d}$ and then decreased to $2 \%$ within $60 \mathrm{~d}$ in $\mathrm{S}_{\mathrm{IN}}$. F4 increased from $11 \%$ to about $49 \%$ within $30 \mathrm{~d}$ and then decreased slowly to $44 \%$ in the later incubation $(60 \mathrm{~d}-180 \mathrm{~d})$ in $\mathrm{S}_{\mathrm{N}}$. By contrast, $F 4$ in $\mathrm{S}_{\text {IN }}$ was shown a remarkable decrease from $63 \%$ to $31 \%$ within $180 \mathrm{~d}$. F5 in both of $\mathrm{S}_{\mathrm{N}}$ and $\mathrm{S}_{\mathrm{IN}}$ increased within $180 \mathrm{~d}$ and were from $4 \%$ and $11 \%$ of the total As to $22 \%$ and $18 \%$, respectively. $F 6$ in $S_{\mathrm{N}}$ increased from $12 \%$ to $17 \%$ and reached a steady state within $60 \mathrm{~d}$, while in $\mathrm{S}_{\mathrm{IN}}$ a remarkable increase from $13 \%$ to $48 \%$ within $180 \mathrm{~d}$ was exhibited. Compared to As fractions in $\mathrm{S}_{\mathrm{N}}$, the proportions of $F 1, F 2, F 3, F 4$, and $F 5$ in $\mathrm{S}_{\mathrm{IN}}$ were lower, while the proportion of $F 6$ in $\mathrm{S}_{\mathrm{IN}}$ was higher after the incubation. This indicates that iron grit is an effective amendment to stabilize As fractions in soils.

The sum of weakly bound fractions of As after amended is usually used to assess the effectiveness of amendments reducing As bioaccessibility in soils $[15,16]$. In this study, the sum of $F 1, F 2$, and $F 3$ to the total As, denoted as $\mathrm{F}_{\mathrm{M}}$, represents the bioaccessibility of As in soils [9]. $\mathrm{F}_{\mathrm{M}}$ in both of $\mathrm{S}_{\mathrm{N}}$ and $\mathrm{S}_{\mathrm{IN}}$ showed a significant decrease from $73 \%$ and $13 \%$ to $17 \%$ and $2 \%$, respectively, and reached a steady state within $60 \mathrm{~d}$ (Figure 2). Therefore, in terms of the As bioaccessibility,

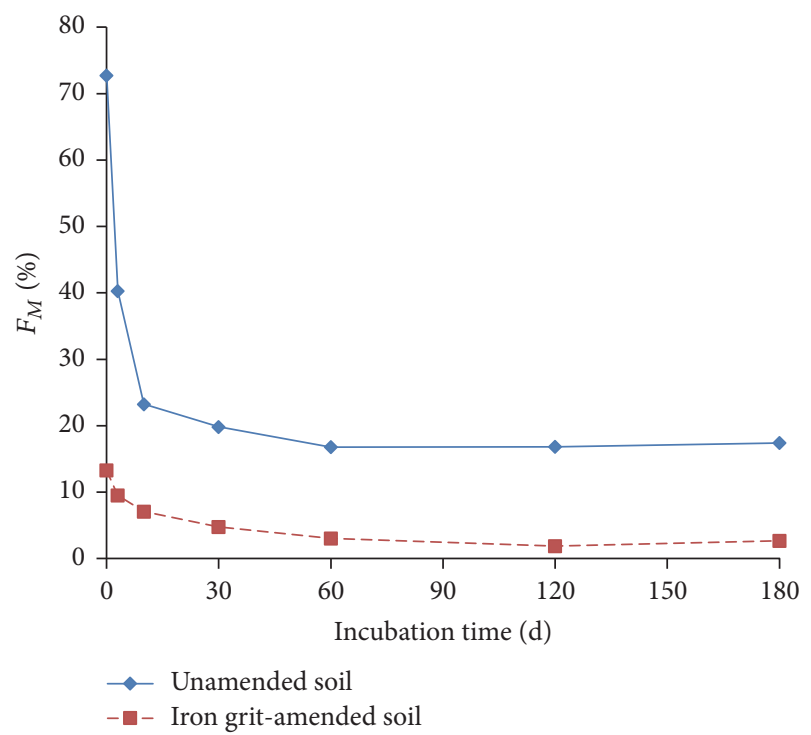

FIGURE 2: Changes of As bioaccessibility in soils under anoxic conditions (unamended soil, $\mathrm{S}_{\mathrm{N}}$; iron grit amended, $\mathrm{S}_{\mathrm{IN}}$ ).

the stabilization/aging processes of As in both of $S_{N}$ and $S_{\text {IN }}$ occur and end within $60 \mathrm{~d}$, and the addition of iron grit is more effective on the stabilization of As in soils.

\subsection{Effect of Redox Conditions on As Fractions in Iron-} Amended Soils. $F 1$ in both of $\mathrm{S}_{\text {IA }}$ and $\mathrm{S}_{\text {IN }}$ decreased markedly within the first $10 \mathrm{~d}$ following the addition of water soluble As and iron grit (Figure 3). By contrast, in the incubation 

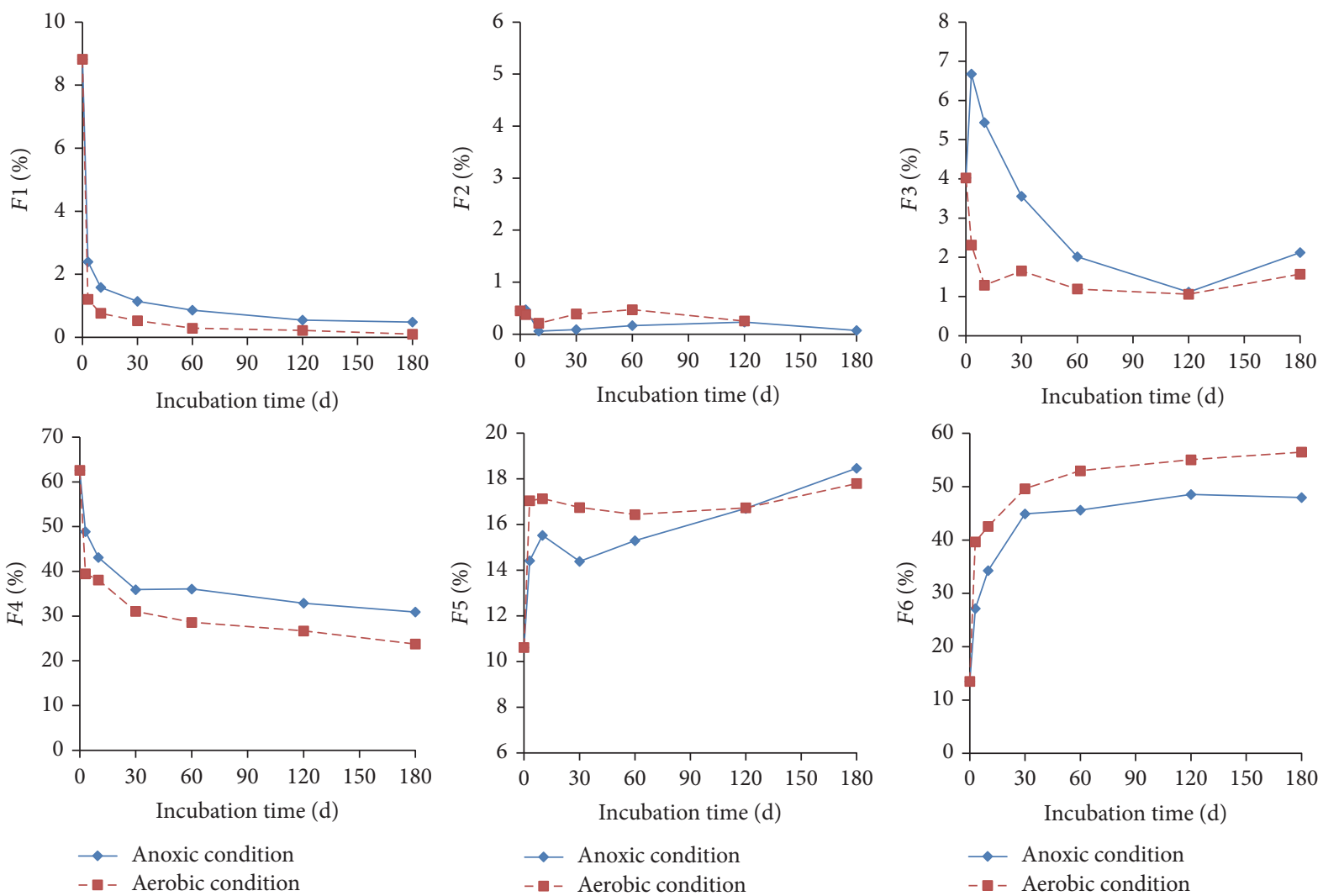

FIgURE 3: Changes of As fractions in iron grit amended soils under different redox conditions over time (anoxic condition, $\mathrm{S}_{\text {IN }}$; aerobic condition, $\left.\mathrm{S}_{\mathrm{IA}}\right)$.

time of $60 \mathrm{~d}$ to $180 \mathrm{~d}$, the changes of $F 1$ in these two soils were distinct; in this period, $F 1$ exhibited further decreases at slow rates and the tendency was not complete at the end of incubation in $S_{\text {IN }}$, while $F 1$ in $S_{\text {IA }}$ had no significant change in $60 \mathrm{~d}-180 \mathrm{~d}$. This indicates that the transformation of $F 1$ into less mobilizable fractions in iron-amended soils under the anoxic condition is a long-term $(>180 \mathrm{~d})$ process, while it is a short-term $(<60 \mathrm{~d})$ process in iron-amended soils under the aerobic condition. Moreover, in the whole incubation period, the proportion of $F 1$ in $\mathrm{S}_{\mathrm{IN}}$ was higher than that in $S_{\text {IA }}$, indicating that more soluble As in iron-amended soils transformed into less mobilizable fractions under aerobic condition in comparison with under anoxic condition. This is likely to be attribute to the ongoing reduction of $\operatorname{As}(\mathrm{V})$ to As(III) in soils under anoxic condition and the higher adsorption of $\mathrm{As}(\mathrm{V})$ than $\mathrm{As}(\mathrm{III})$ onto soil components [10, $11,17,18]$.

Different from $F 1$, there was no significant difference of $F 2$ in both $\mathrm{S}_{\text {IA }}$ and $\mathrm{S}_{\text {IN }}$, and the proportion of $F 2$ exhibited a negligible level during the whole incubation time (Figure 3). So it could be speculated that $F 2$ was converted to less mobilizable fractions at an extremely fast rate following the addition of iron grit to soils whether in an oxidizing environment or in a reducing environment. This may be ascribed to the rapidly formed Fe oxides after the addition of iron grit into soils, because the rapid adsorption of added As on the surface of newly formed amorphous iron oxides has been found [19].
$F 3$ in $\mathrm{S}_{\text {IA }}$ showed a marked decrease and reached a steady state quickly within the first $10 \mathrm{~d}$ (Figure 3). By contrast, F3 in $\mathrm{S}_{\text {IN }}$ exhibited a significant increase within the first $3 \mathrm{~d}$ and then decreased, indicating that the redistribution of $F 3$ in iron-amended soils under anoxic conditions occurred. The reason for the increase of $F 3$ in $S_{\text {IN }}$ within the first $3 \mathrm{~d}$ may be as follows: on the one hand, $\mathrm{pH}$ in $\mathrm{S}_{\mathrm{IN}}$ may increase within the first $3 \mathrm{~d}$, because soil $\mathrm{pH}$ increased slightly after the flood while $\mathrm{pH}$ in nonflooded soil showed little change [20]; on the other hand, the reduction of $\mathrm{As}(\mathrm{V})$ to As(III) often occurs in soils under anoxic conditions [12], both leading to the increase of $F 3$ in $\mathrm{S}_{\text {IN }}$ within the first $3 \mathrm{~d}$, because $\mathrm{As}(\mathrm{III})$ is preferentially nonspecific adsorbed to Fe-hydroxides at alkaline condition [2]. As on external surface of soil minerals gradually diffuses into inner surface and mineral lattice and forms relatively immobilizable surface complexes and insoluble secondary solid phases [10,21], which may be responsible for the decrease of $F 3$ in iron-amended soils with the contact time. The change of $F 3$ in $\mathrm{S}_{\text {IA }}$ ended in the first $10 \mathrm{~d}$ while in $S_{\text {IN }}$ it ended within $60 \mathrm{~d}$, indicating that the transformation of $F 3$ into other fractions in iron-amended soils under the anoxic condition is more lasting than that under the aerobic condition.

Similar to $F 1$ in soils, $F 4$ also showed a significant decrease in both $S_{I A}$ and $S_{I N}$, and the decrease of $F 4$ was not complete within the incubation time in both $\mathrm{S}_{\text {IA }}$ and $\mathrm{S}_{\text {IN }}$ (Figure 3). This indicates that effect of redox conditions on the tendency of F4 in iron-amended soils is negligible. The 
decomposition of organic matter and the increase of crystallization of Fe oxides with the contact time may be responsible for the decrease of $F 4$ in iron-amended soils $[10,22,23]$. In addition, the proportion of $F 4$ in $\mathrm{S}_{\text {IN }}$ was significantly higher than that in $\mathrm{S}_{\text {IA }}$ during the whole incubation period. This may be attributed to the more $\mathrm{As}(\mathrm{V})$ reduction to $\mathrm{As}(\mathrm{III})$ and less decomposition of dissolved organic matters in soils under anoxic condition than that under aerobic condition $[8,11]$.

Contrary to the four former fractions, $F 5$ in both $S_{\text {IA }}$ and $S_{\text {IN }}$ increased promptly within the first $10 \mathrm{~d}$ after the addition of water soluble As and iron grit (Figure 3). In contrast, during the later incubation period $(10 \mathrm{~d}-180 \mathrm{~d})$, the changes of $F 5$ in these two soils were distinct: $F 5$ in $\mathrm{S}_{\text {IA }}$ reached the equilibrium within the first $10 \mathrm{~d}$, while in $S_{\text {IN }}$ it exhibited a further increase in the later incubation period $(10 \mathrm{~d}-180 \mathrm{~d})$. This indicates that the transformation of $F 5$ into other fractions in iron-amended soils under the anoxic condition is a long-term $(>180 \mathrm{~d})$ process, while it is a shortterm $(<10 \mathrm{~d})$ process in iron-amended soils under the aerobic condition. The reductive dissolution and reproduction of AsFe phases in soils occur under reducing conditions, but it is inhibited at oxidative conditions, which may be responsible for the different tendency of $F 5$ in $\mathrm{S}_{\mathrm{IA}}$ and $\mathrm{S}_{\mathrm{IN}}[17,24]$. It is worth mentioning that the proportion of $F 5$ in $\mathrm{S}_{\mathrm{IN}}$ was significantly lower than that in $\mathrm{S}_{\text {IA }}$ during the incubation period of $3 \mathrm{~d}-60 \mathrm{~d}$. This may be ascribed to the reduction of $\mathrm{As}(\mathrm{V})$ into As(III) and the poor crystallization of Fe oxides in soils under the anoxic condition [10].

F6 in both $\mathrm{S}_{\text {IA }}$ and $\mathrm{S}_{\text {IN }}$ increased markedly within the first $30 \mathrm{~d}$ following the addition of As and iron grit (Figure 3). The changes of $F 6$ in these two soils in the later incubation period $(30 \mathrm{~d}-180 \mathrm{~d})$ were distinct: $F 6$ in $S_{\text {IN }}$ reached the equilibrium within the first $30 \mathrm{~d}$, while in $S_{\text {IA }}$ it showed a further increase at slow rates and the tendency was not complete within $180 \mathrm{~d}$. This indicates that aerobic condition is likely to prolong the formation of $F 6$ in iron-amended soils in comparison with anoxic condition. This may be attributed to the lasting well crystallization of Fe oxides in iron-amended soils under the aerobic condition. The proportion of $F 6$ in $\mathrm{S}_{\text {IN }}$ was significantly lower than that in $\mathrm{S}_{\text {IA }}$ during the whole incubation period. This indicates that the aerobic condition likely leads to the more increase of $F 6$ in iron-amended soils over time in comparison with the anoxic condition. Reduction of $\mathrm{As}(\mathrm{V})$ to $\mathrm{As}(\mathrm{III})$ under the anoxic condition over time may be also responsible for the above effect, because a higher proportion of labile fraction of As(V) commonly transforms into less mobilizable fractions, such as F6, in soils over time in comparison with As(III) [10].

\subsection{Impact of Redox Conditions on As Bioaccessibility in} Iron-Amended Soils. As shown in Figure 4, $\mathrm{F}_{\mathrm{M}}$ in both $\mathrm{S}_{\mathrm{IA}}$ and $\mathrm{S}_{\mathrm{IN}}$ decreased rapidly within the first $10 \mathrm{~d}$ following the addition of $\mathrm{As}(\mathrm{V})$ and iron grit into the soils. In contrast, the changes of $\mathrm{F}_{\mathrm{M}}$ in these two soils in the later incubation period $(10 \mathrm{~d}-180 \mathrm{~d})$ were distinct: $\mathrm{F}_{\mathrm{M}}$ in $\mathrm{S}_{\mathrm{IA}}$ reached the equilibrium within the first $10 \mathrm{~d}$, while in $\mathrm{S}_{\mathrm{IN}}$ it showed a further decrease and reached the equilibrium within $120 \mathrm{~d}$. This indicates that anoxic condition would lead to the tendency of $\mathrm{F}_{\mathrm{M}}$ in iron-amended soils reaching equilibrium

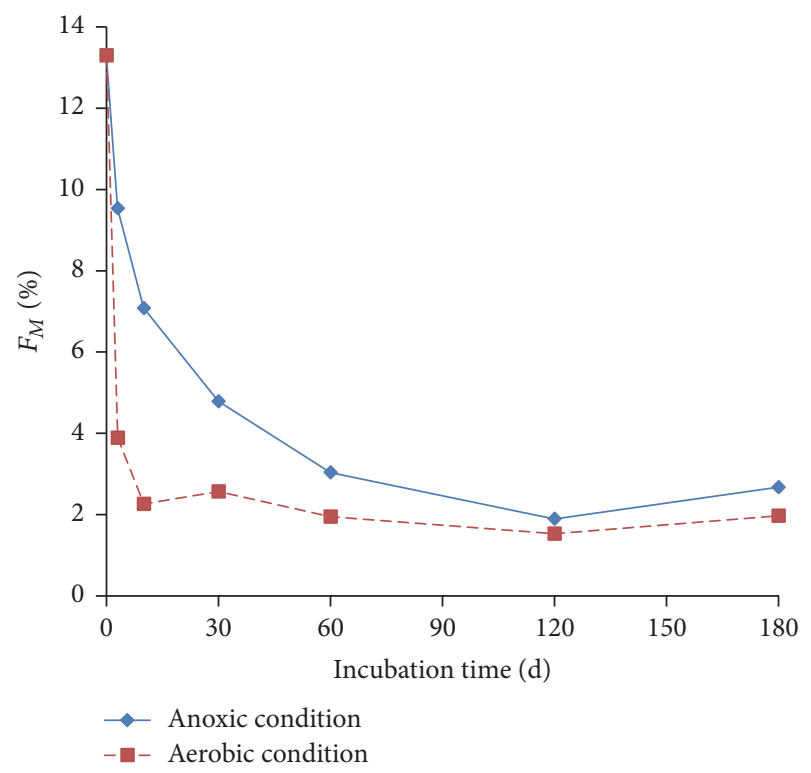

FIgURE 4: Changes of As bioaccessibility in soils under different redox conditions after the addition of iron grit over time (anoxic condition, $\mathrm{S}_{\mathrm{IN}}$; aerobic condition, $\mathrm{S}_{\mathrm{IA}}$ ).

later in comparison with aerobic condition. In terms of As bioaccessibility, the stabilization process ended within $10 \mathrm{~d}$ in $S_{I A}$, but it was complete within $120 \mathrm{~d}$ in $S_{I N}$, indicating that the anoxic condition would prolong the stabilization process of As in iron-amended soils. In addition, over the whole incubation period, the proportion of $F_{M}$ in $S_{I N}$ was higher than that in $S_{I A}$, which demonstrates that the aerobic condition tended to be more conducive to reduced bioaccessibility of As than anoxic condition. It is likely to be coaffected by the reductive dissolution of $\mathrm{Fe}$ (hydr)oxides and the reduction of $\mathrm{As}(\mathrm{V})$ to $\mathrm{As}(\mathrm{III})$ at anoxic condition $[25,26]$, because As which was coprecipitated and adsorbed on Fe(hydr)oxides surface could be released due to the reductive dissolution of the $\mathrm{Fe}$ oxides and the lower adsorption of $\mathrm{As}(\mathrm{III})$ onto the surface of soil minerals than that of $\mathrm{As}(\mathrm{V})$ [27].

3.4. Effect of Redox Conditions on the Stabilization Processes of As in Iron-Amended Soils. The stabilization process of As in $\mathrm{S}_{\mathrm{IN}}$ had two distinct stages in the whole incubation period (Figure 5(a)). The first stage was from $0 \mathrm{~d}$ to $3 \mathrm{~d}$, where $F 1$ and $F 4$ decreased and, in contrast, $F 3, F 5$, and $F 6$ increased, while other fractions exhibited no marked change, indicating that $F 1$ and $F 4$ transformed into $F 3, F 5$, and $F 6$ in $S_{\text {IN }}$ within the first $3 \mathrm{~d}$, and the main transformation was from $F 1$ and $F 4$ to $F 6$ due to their large variations. In this stage, transformation of $F 1$ to $F 6$ in $S_{\text {IN }}$ was likely to be affected by the molecular diffusion in micropores of the soil minerals $[9,10]$. Transformation of $F 4$ to $F 6$ in $S_{\text {IN }}$ was coaffected by the decomposition of organic matter and molecular diffusion in the surface of soil minerals [22], because As occluded within organic matters would be released again after the decomposition of arganic matter by microbial respiration under the anoxic condition and then diffused into the mineral 


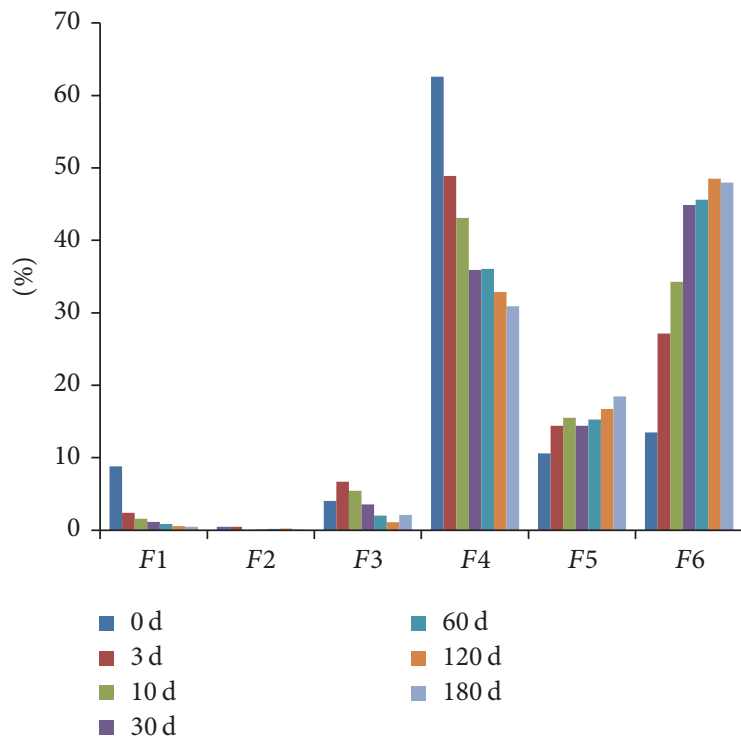

(a)

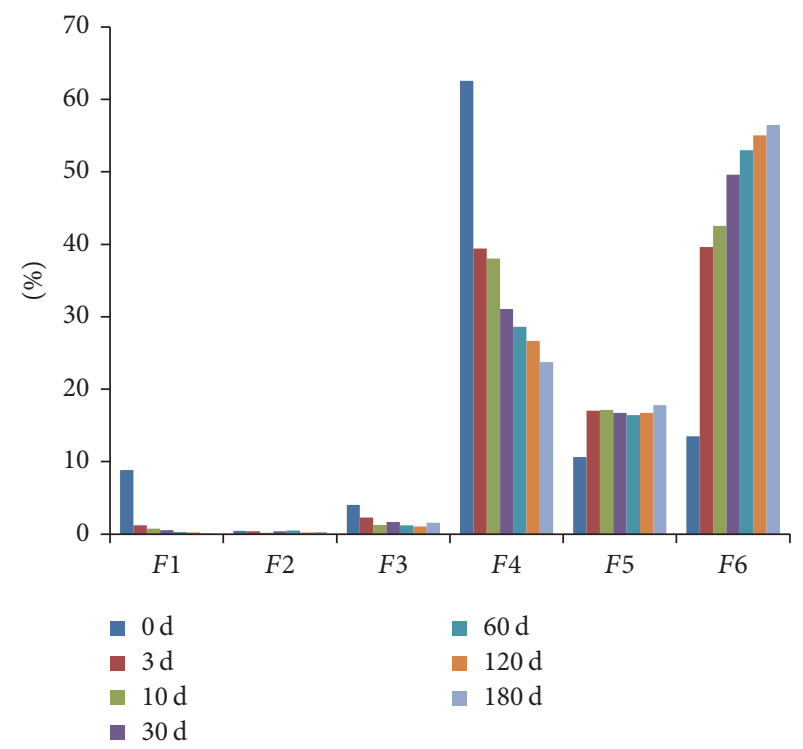

(b)

FIGURE 5: The stabilization processes of As in soils at different redox conditions ((a) $S_{\text {IN }}$ and (b) $S_{\text {IA }}$ ).

lattice [10]. The second stage in $\mathrm{S}_{\mathrm{IN}}$ was from $3 \mathrm{~d}$ to $180 \mathrm{~d} ; F 1$, $F 3$, and F4 decreased and, in contrast, F5 and F6 increased, while $F 2$ was without significant change. This indicates that three more mobilizable fractions transformed into two less mobilizable or immobilizable fractions in the later incubation time in $S_{\text {IN }}$. The main transformation in $S_{\text {IN }}$ in the second stage was also from $F 4$ to $F 6$ due to their large variations, and the decomposition of organic matter and molecular diffusion in the surface of soil minerals should be responsible for this transformation.

Similar to the iron-amended soils under anoxic condition, the stabilization process of As in iron-amended soils under aerobic condition also had two distinct stages in the whole incubation period (Figure 5(b)). The first stage was also within the first $3 \mathrm{~d}$, where $F 1, F 3$, and $F 4$ decreased and, in contrast, $F 5$ and $F 6$ increased, while $F 2$ was without significant change. This indicates that three more labile fractions transformed into two unlabile fractions in $S_{\text {IA }}$ within the first $3 \mathrm{~d}$. The main transformation in $\mathrm{S}_{\mathrm{IA}}$ in the first stage was from $F 1$ to $F 5$ and $F 4$ to $F 6$ due to their large variations. In this stage, the transformation of $F 1$ to $F 5$ in $\mathrm{S}_{\mathrm{IA}}$ may be ascribed to the well crystallization of $\mathrm{Fe}$ oxides and As occluded within $\mathrm{Fe}$-(hydr)oxides, because the crystallization of $\mathrm{Fe}$ oxides in soils under aerobic conditions would occur rapidly [28]. The transformation of F4 to F6 in $\mathrm{S}_{\mathrm{IA}}$ is also likely to be attributed to the decomposition of organic matter and molecular diffusion in the surface of soil minerals. The second stage in $\mathrm{S}_{\text {IA }}$ was also from $3 \mathrm{~d}$ to $180 \mathrm{~d}$; $F 1$ and $F 4$ decreased and, in contrast, F6 increased, while other fractions showed no significant change, indicating the transformation of $F 1$ and $F 4$ into $F 6$ in $\mathrm{S}_{\mathrm{IA}}$ in the later incubation period. In this stage, the main transformation in $\mathrm{S}_{\mathrm{IA}}$ was $F 4$ to $F 6$, and the reason was discussed as in the above.

\section{Conclusions}

The present study demonstrated that water soluble and loosely adsorbed As was the primary fractions in soils spiked As(V). After the addition of iron grit, the primary fractions of As in soils were characterized by strongly adsorbed and organically bound fractions $(\sim 63 \%)$, while the water soluble and loosely adsorbed As only account for a small proportion. More labile fractions transformed into immobilizable factions in iron-amended soils under aerobic conditions in comparison with under anoxic conditions. The redistribution of $F 3$ in iron-amended soils under anoxic conditions occurs, as a result of the reduction of $\mathrm{As}(\mathrm{V})$ to $\mathrm{As}(\mathrm{III})$ and the reductive dissolution of $\mathrm{Fe}$-(hydr)oxides.

The stabilization processes of As in iron-amended soils under the anoxic and aerobic conditions were characterized by two stages. The increase of crystallization of Fe oxides, decomposition of organic matter, molecular diffusion, and the occlusion within Fe-(hydr)oxides cocontrolled the transformation of As fractions and the stabilization process of As in iron-amended soils under different redox conditions. In terms of As bioaccessibility, the stabilization process of As in iron-amended soils was shortened under the aerobic condition in comparison with under the anoxic condition.

\section{Conflicts of Interest}

The authors declare that they have no conflicts of interest.

\section{Acknowledgments}

This research was supported by the Natural Science Foundation of Hebei Province of China (D2015504004), the Fundamental Research Funds for Central Public Welfare Research 
Institutes, CAGS (SK201611, SK201410), China Geological Survey project (DD20160309), and the National Natural Science Foundation of China (41472264, 41772334).

\section{References}

[1] C. N. Mulligan, R. N. Yong, and B. F. Gibbs, "Remediation technologies for metal-contaminated soils and groundwater: an evaluation," Engineering Geology, vol. 60, no. 1-4, pp. 193-207, 2001.

[2] P. Miretzky and A. F. Cirelli, "Remediation of arsenic-contaminated soils by iron amendments: A review," Critical Reviews in Environmental Science and Technology, vol. 40, no. 2, pp. 93115, 2010.

[3] B. Song, G. Zeng, J. Gong et al., "Evaluation methods for assessing effectiveness of in situ remediation of soil and sediment contaminated with organic pollutants and heavy metals," Environment International, vol. 105, pp. 43-55, 2017.

[4] C. Tiberg, J. Kumpiene, J. P. Gustafsson et al., "Immobilization of $\mathrm{Cu}$ and As in two contaminated soils with zero-valent iron - Long-term performance and mechanisms," Applied Geochemistry, vol. 67, pp. 144-152, 2016.

[5] M. Komárek, A. Vaněk, and V. Ettler, "Chemical stabilization of metals and arsenic in contaminated soils using oxides - A review," Environmental Pollution, vol. 172, pp. 9-22, 2013.

[6] T. Makino, K. Nakamura, H. Katou et al., "Simultaneous decrease of arsenic and cadmium in rice (Oryza sativa L.) plants cultivated under submerged field conditions by the application of iron-bearing materials," Soil Science \& Plant Nutrition, vol. 62, no. 4, pp. 340-348, 2016.

[7] J. Kumpiene, A. Lagerkvist, and C. Maurice, "Stabilization of As, $\mathrm{Cr}, \mathrm{Cu}, \mathrm{Pb}$ and $\mathrm{Zn}$ in soil using amendments-a review," Waste Management, vol. 28, no. 1, pp. 215-225, 2008.

[8] S. M. Shaheen, J. Rinklebe, T. Frohne, J. R. White, and R. D. DeLaune, "Redox effects on release kinetics of arsenic, cadmium, cobalt, and vanadium in Wax Lake Deltaic freshwater marsh soils," Chemosphere, vol. 150, pp. 740-748, 2016.

[9] G. Huang, Z. Chen, J. Wang, Q. Hou, and Y. Zhang, "Impact of temperature on the aging mechanisms of arsenic in soils: fractionation and bioaccessibility," Environmental Science and Pollution Research, vol. 23, no. 5, pp. 4594-4601, 2016.

[10] G. Huang, Z. Chen, Y. Zhang, F. Liu, J. Wang, and Q. Hou, "Changes of arsenic fractionation and bioaccessibility in wastewater-irrigated soils as a function of aging: Influence of redox condition and arsenic load," Geoderma, vol. 280, pp. 1-7, 2016.

[11] Q. Hou, Y. Zhang, L. Li, and S. Song, "Effects of particle size and redox potential on arsenic fractionation in soils irrigated with arsenate-rich water," Soil and Sediment Contamination: An International Journal, vol. 26, no. 4, pp. 391-403, 2017.

[12] G. Huang, Z. Chen, J. Sun, F. Liu, J. Wang, and Y. Zhang, "Effect of sample pretreatment on the fractionation of arsenic in anoxic soils," Environmental Science and Pollution Research, vol. 22, no. 11, pp. 8367-8374, 2015.

[13] G. Huang, Z. Chen, F. Liu, J. Sun, and J. Wang, "Impact of human activity and natural processes on groundwater arsenic in an urbanized area (South China) using multivariate statistical techniques," Environmental Science and Pollution Research, vol. 21, no. 22, pp. 13043-13054, 2014.

[14] M. Vítková, S. Rákosová, Z. Michálková, and M. Komárek, "Metal(loid)s behaviour in soils amended with nano zero-valent iron as a function of $\mathrm{pH}$ and time," Journal of Environmental Management, vol. 186, pp. 268-276, 2017.
[15] J.-Y. Kim, A. P. Davis, and K.-W. Kim, "Stabilization of available arsenic in highly contaminated mine tailings using iron," Environmental Science \& Technology, vol. 37, no. 1, pp. 189-195, 2003.

[16] M. Simón, V. González, S. de Haro, and I. García, "Are soil amendments able to restore arsenic-contaminated alkaline soils?" Journal of Soils and Sediments, vol. 15, no. 1, pp. 117-125, 2014.

[17] S. Matsumoto, J. Kasuga, N. Taiki, T. Makino, and T. Arao, "Inhibition of arsenic accumulation in Japanese rice by the application of iron and silicate materials," Catena, vol. 135, pp. 328-335, 2015.

[18] N. Bolan, A. Kunhikrishnan, R. Thangarajan et al., "Remediation of heavy metal(loid)s contaminated soils-to mobilize or to immobilize?" Journal of Hazardous Materials, vol. 266, pp. 141-166, 2014.

[19] S. C. Wilson, P. V. Lockwood, P. M. Ashley, and M. Tighe, "The chemistry and behaviour of antimony in the soil environment with comparisons to arsenic: a critical review," Environmental Pollution, vol. 158, no. 5, pp. 1169-1181, 2010.

[20] S. Das, M.-L. Chou, J.-S. Jean, C.-C. Liu, and H.-J. Yang, "Water management impacts on arsenic behavior and rhizosphere bacterial communities and activities in a rice agro-ecosystem," Science of the Total Environment, vol. 542, pp. 642-652, 2016.

[21] S. Hafeznezami, A. G. Zimmer-Faust, D. Jun et al., "Remediation of groundwater contaminated with arsenic through enhanced natural attenuation: Batch and column studies," Water Research, vol. 122, pp. 545-556, 2017.

[22] C. T. Parsons, R.-M. Couture, E. O. Omoregie et al., "The impact of oscillating redox conditions: Arsenic immobilisation in contaminated calcareous floodplain soils," Environmental Pollution, vol. 178, pp. 254-263, 2013.

[23] J. Kumpiene, J. P. Fitts, and M. Mench, "Arsenic fractionation in mine spoils 10 years after aided phytostabilization," Environmental Pollution, vol. 166, pp. 82-88, 2012.

[24] P. Hu, Y. Ouyang, L. Wu, L. Shen, Y. Luo, and P. Christie, "Effects of water management on arsenic and cadmium speciation and accumulation in an upland rice cultivar," Journal of Environmental Sciences, vol. 27, no. C, pp. 225-231, 2015.

[25] A. Neumann, R. Kaegi, A. Voegelin, A. Hussam, A. K. M. Munir, and S. J. Hug, "Arsenic removal with composite iron matrix filters in Bangladesh: a field and laboratory study," Environmental Science \& Technology, vol. 47, no. 9, pp. 4544-4554, 2013.

[26] Z. Zhao, S. Wang, and Y. Jia, "Effect of sulfide on As(III) and As(V) sequestration by ferrihydrite," Chemosphere, vol. 185, pp. 321-328, 2017.

[27] J. Beiyuan, Y. M. Awad, F. Beckers, D. C. W. Tsang, Y. S. Ok, and J. Rinklebe, "Mobility and phytoavailability of As and $\mathrm{Pb}$ in a contaminated soil using pine sawdust biochar under systematic change of redox conditions," Chemosphere, vol. 178, pp. 110-118, 2017.

[28] A. Thompson, O. A. Chadwick, D. G. Rancourt, and J. Chorover, "Iron-oxide crystallinity increases during soil redox oscillations," Geochimica et Cosmochimica Acta, vol. 70, no. 7, pp. 17101727, 2006. 

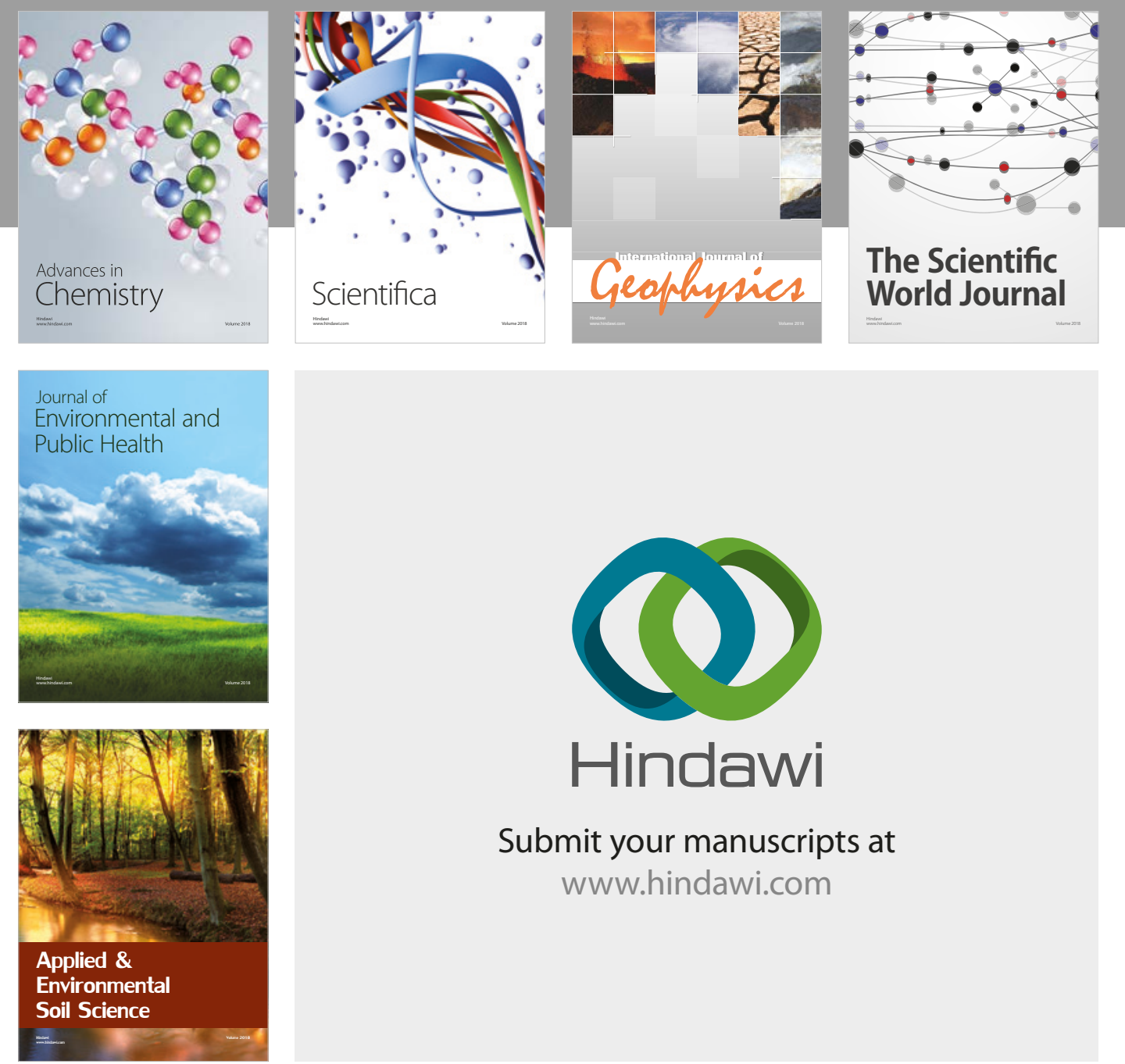

The Scientific

\section{World Journal}
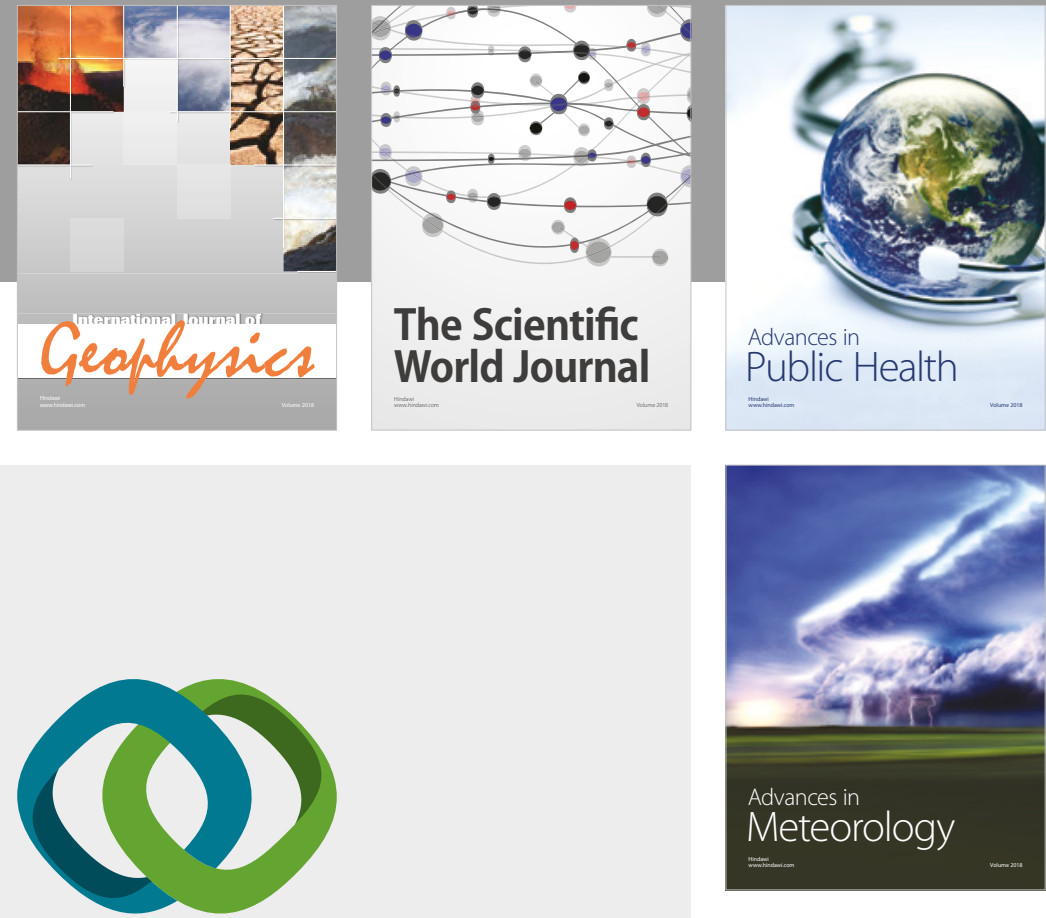

Advan

Public Health

\section{Hindawi}

Submit your manuscripts at

www.hindawi.com
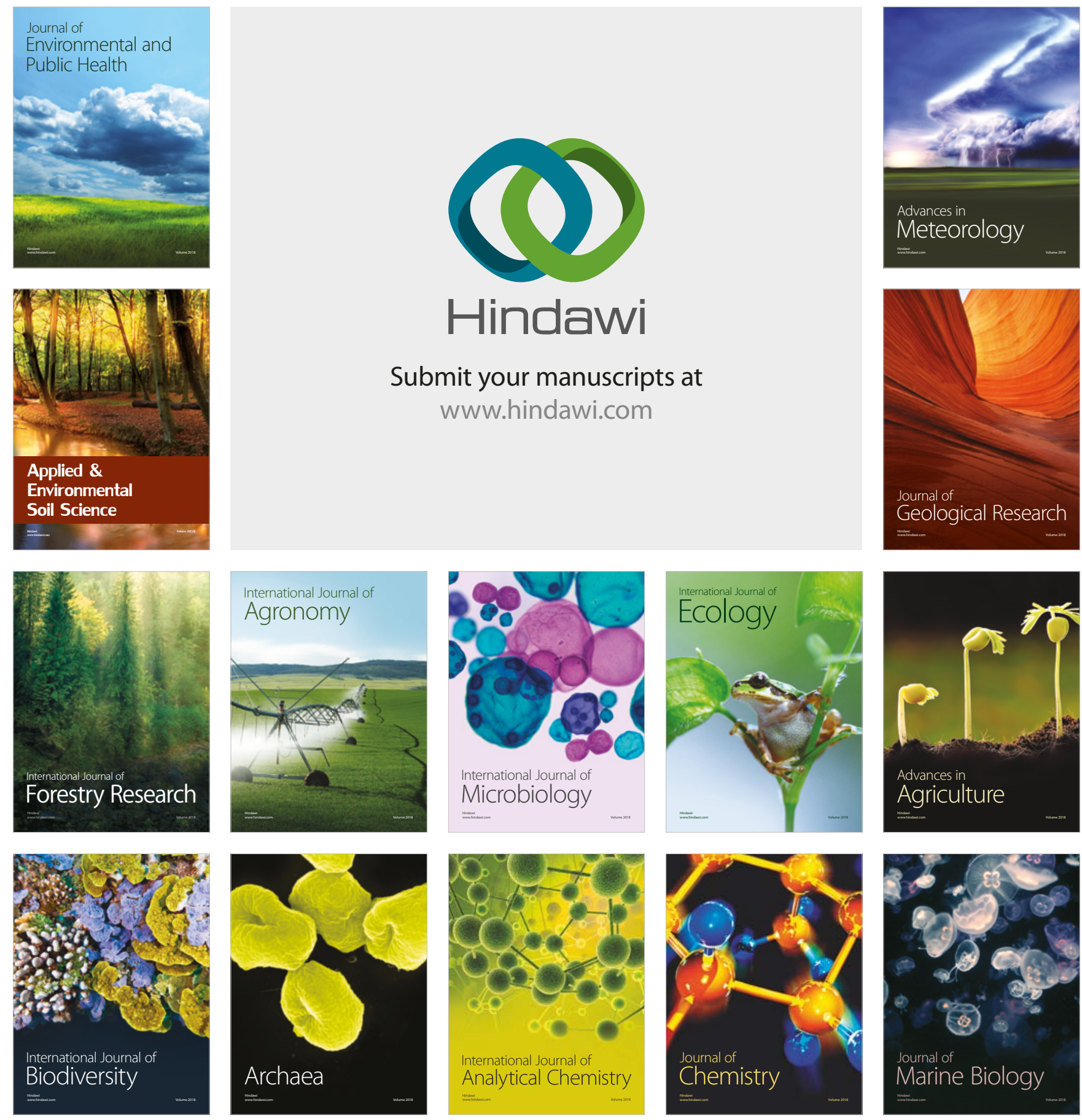